\title{
RATE OF AMMONIUM SULFITE OXIDATION IN AQUEOUS SOLUTIONS*
}

\author{
AKINORI MATSUURA, JUMEI HARADA, TAKASHI AKEHATA,
} AND TAKASHI SHIRAI

Research Laboratory of Resources Utilization,

Tokyo Institute of Technology, Tokyo

\begin{abstract}
The rate of the homogeneous reaction of dissolved oxygen and ammonium sulfite in aqueous solutions without catalysts, which has industrial importance in recovery of sulfur dicxide, was studied at 20,25 and $30^{\circ} \mathrm{C}$. A polarographic method using a platinum microelectrode was employed for the determination of the oxygen concentration during the course of reaction. 'Two reactors of different size, which contained 0.5 and $4.7 l$ of solution, respectively, were found to give essentially the same results. The rate of ammonium sulfite oxidation was found to be about one tenth of that of sodium sulfite. The influence of impurities on the rate was found very remarkable. The existence of inhibitors suggested that the reaction might be a radical one. An empirical rate equation, $r=k\left[\mathrm{SO}_{3}{ }^{2-}\right]^{3 / 2}\left[\mathrm{O}_{2}\right]^{0}\left[\mathrm{H}^{+}\right]^{2}$ in $\mathrm{M} \cdot \mathrm{min}^{-1}$ with $k=1.6 \times 10^{39} \exp \left(-35 \times 10^{3} / \mathrm{RT}\right)$, was obtained in the experimental range of this work.
\end{abstract}

\section{Introduction}

Recently an increasing interest in the prevention of air pollution in cities makes it appear probable that power plants may be required to remove sulfur dioxide from stack gas. The use of ammonium solution for the recovery of sulfur dioxide from flue gas has been noted ${ }^{12)}$, and this treatment is followed by liquid-phase oxidation of ammonium sulfite, which may prove to be of commercial importance. In fact, the oxidation of ammonium sulfite in aqueous solution has been industrially employed to produce ammonium sulfate ${ }^{7)}$. The process involves oxygen transfer from gas phase to the sulfite solution and the reaction proceeds rapidly without catalysts. It is said that large over-all reaction rates are achieved by a large interfacial area.

$\mathrm{Hori}^{7)}$ found that in batchwise experiments the conversion of sulfite was roughly proportional to the period of time of bubbling gaseous oxygen into a solution. Vorländer and Lainau ${ }^{15}$ observed that the absorption rate of gaseous oxygen increased linearly with the sulfite concentration, but beyond a certain value of the concentration the absorption rate decreased slightly with increase in the sulfite concentration. Young ${ }^{17)}$ made a qualitative experiment on the absorption rates of oxygen into sulfurous acid solutions with various co-existing ions by a manometric measurement, and reported that the absorption rate into a sodium sulfite solution was larger than that into an ammonium sulfite solution. However, a detailed study and the rate equation of ammonium sulfite oxidation in aqueous solutions were not reported.

* Received on December 23, 1968

This work was presented at Hokkaido Meeting of the Society of Chemical Engineers, Japan, at Sapporo, Aug., 1968.
On the other hand, the kinetics of the sodium sulfite oxidation have been researched by a number of workers ${ }^{1 \sim 4,10 \sim 11,14 \sim 17)}$.

The purpose of this paper is firstly to present the rate data of homogeneous liquid-phase oxidation of ammonium sulfite without catalyst, and secondly to establish a rate equation useful for design calculation in consideration of the effects of reactant concentrations and reaction temperature on the rate.

\section{Experimental}

Experimental apparatus Two reactors used were made of glass and contained about 0.5 and $4.7 l$ of solution, respectively. The experimental apparatus for the small reactor is shown schematically in Fig. 1. The reactor was immersed in a water bath and the bath temperature was adjusted to a desired temperature by a mercury-toluene regulator within 0.1 ${ }^{\circ} \mathrm{C}$ of variation. A rotating platinum microelectrode consisted of a platinum wire $5.0 \mathrm{~mm}$. long and 0.3 $\mathrm{mm}$. in diameter projecting from a glass shaft, which was rotated at 50 r.p.m. by a synchronous motor. Two blades were provided on the end of the shaft to agitate the solution. The platinum anode plate, which had no catalytic effect on the reaction as will be discussed later, had a surface area much larger than that of the microelectrode. Ammonium sulfate of special grade was used as a supporting electrolyte. The reactor had a glass capillary for bubbling oxygen and an auxiliary stirrer for initial mixing of solution.

When the large reactor equipped with four standard glass baffles was used, a four-straight-blades turbine impeller was rotated at 100 r.p.m. in the center of the vessel. For measurement of the oxygen concentration, a stationary spherical platinum micro- 


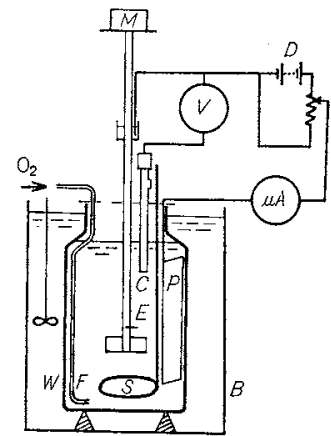

B Water bath

C Saturated calomel electrode

D Regulated D. C. supply

E Platinum microelectrode

F Gas bubbler

M Synchronous motor

P Platinum anode plate

S Auxiliary stirrer

$\mathrm{V}$ Voltmeter

W Reaction vessel

$\mu \mathrm{A}$ Microamperemeter

Fig. I Schematic view of experimental apparatus

electrode was immersed in the solution.

Distilled water was prepared by distilling an alka. line-permanganate solution of de-ionized water. Ammonium sulfite solutions of various $\mathrm{pH}$ were prepared by mixing sulfurous acid and ammonia water to proper ratios. The sulfurous acid and ammonia water were prepared, respectively, by bubbling sulfur dioxide and ammonia from cylinders in distilled water. Solutions prepared with ammonium sulfite of reagent grade were also used for some runs. As long-standing solution may produce impurities such as $\mathrm{SO}_{2}$ and $\mathrm{S}_{2} \mathrm{O}_{8}{ }^{2-}$, a fresh sulfite solution was prepared before each run. Use of solution after long storage yielded results of poor reproducibility.

Analysis The dissolved oxygen concentration during each run was determined from the measurement of the diffusion current due to oxygen. The relation between the oxygen concentration, determined by the Winkler method $^{9}$, and its diffusion current at $-0.6 \mathrm{~V}$ to S.C.E. was found to be linear. The relation at $25^{\circ} \mathrm{C}$ is shown/in Fig. 2. It was ascertained in this work that co-existing sulfite and ammonium ions did not disturb the diffusion current due to oxygen under the experimental conditions.

The sulfite concentration was determined by iodometric titration as the total sulfite concentration, $\mathrm{S}_{\mathrm{t}}$ $=\mathrm{SO}_{3}{ }^{2-}+\mathrm{HSO}_{3}{ }^{-}$; the sulfite concentration was calculated from

$$
\frac{\left[\mathrm{SO}_{3}{ }^{2-}\right]}{\left[\mathrm{S}_{\mathrm{t}}\right]}=\frac{1}{\frac{\left[\mathrm{H}^{+}\right]}{K_{2}}+1}
$$

where $K_{2}$ is the apparent second ionization constant of sulfurous acid. Values of $K_{2}$ were reported ${ }^{5,88}$ at 18,20 and $25^{\circ} \mathrm{C}$ as $1.02 \times 10^{-7}, 1.00 \times 10^{-7}$ and 6.24 $\times 10^{-8}$, respectively, and the one at $30^{\circ} \mathrm{C}\left(4.4 \times 10^{-8}\right)$ was estimated by assuming the linear relationship between $\log K_{2}$ and $1 / T$. The sulfite to total sulfite

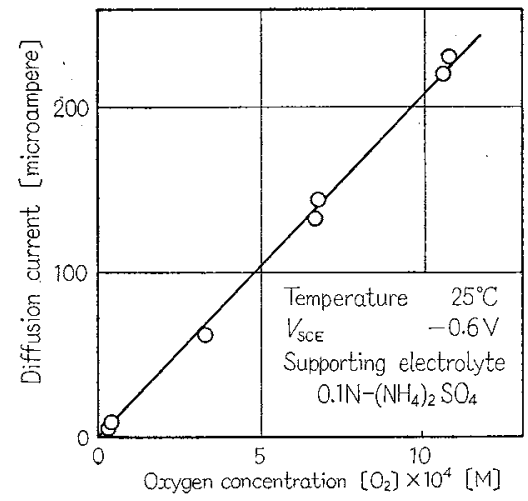

Fig. 2 Relation between diffusion current and oxygen concentration

ratio, $\left[\mathrm{SO}_{3}{ }^{2-}\right] /\left[\mathrm{S}_{t}\right]$, greatly increases from 0.05 to 0.98 , as $\mathrm{pH}$ increases from 5 to 9 .

The $\mathrm{pH}$ of solutions was measured by means of a Beckman-Toshiba $\mathrm{pH}$ meter.

Experimental procedure A known volume of supporting electrolyte solution was charged to the reactor. Oxygen was bubbled through the glass capillary and the oxygen supply was stopped at saturation. Then an ammonium sulfite solution of known concentration was injected to the reactor by using a calibrated syringe, and the solution was agitated by the auxiliary stirrer for about thirty seconds. The potential of the microelectrode was set and retained at $-0.6 \mathrm{~V}$ to S.C.E. and the diffusion current due to oxygen at this potential was recorded as a function of time. The reaction time was measured from the time when the injection of the sulfite solution was started. In all runs the sulfite concentration and $\mathrm{pH}$ of solution were determined at both beginning and end of each run, and for some runs the $\mathrm{pH}$ was measured at appropriate time intervals. The initial concentration of total sulfite was calculated from the concentration and volume of the sulfite solution added to the reactor, and the final concentration was determined iodometrically.

Since a solution of high oxygen concentration desorbed oxygen a little into the gas phase in contact with the reacting liquid and one of very low oxygen concentration absorbed oxygen, the mass transfer coefficient was determined experimentally under the reaction condition, and the coefficient was used for correction of the observed change of oxygen concentration to obtain the reaction rate.

A different experimental procedure was employed for some runs. An ammonium sulfite solution was charged to the reactor first and then gaseous oxygen was bubbled into the solution. When the oxygen concentration reached a certain level, the oxygen supply was stopped and the change of diffusion current was measured as a function of the run time.

Measurements were made by varing the initial total sulfite concentration from 0.0027 to $0.092 \mathrm{M}$, and the initial $\mathrm{pH}$ of reactant solution from 6.55 to 8.03 at 


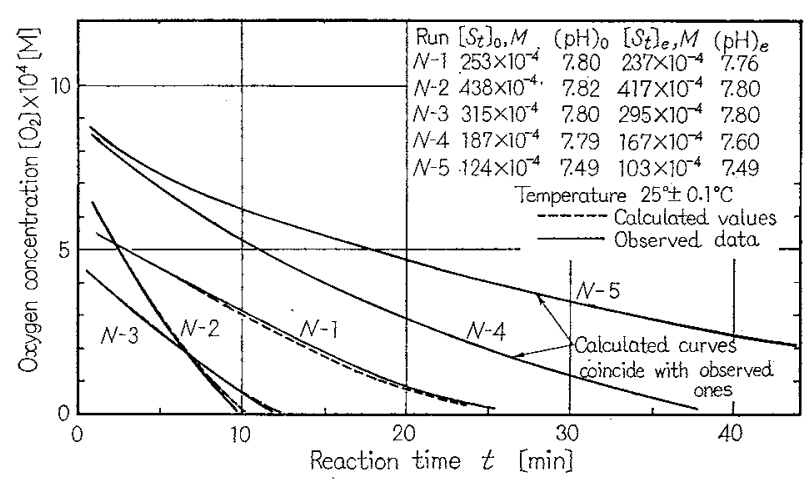

Fig. 3 Change of oxygen concentration with reaction time

temperatures of 20,25 and $30^{\circ} \mathrm{C}$, respectively.

It should be pointed out here that efforts were made both to prevent impurities from coming in with the reactant and to prevent metal from coming in contact with the solution. All the parts of the reactor system except electrodes were made of glass. The reaction vessel was cleaned by a mixture of concentrated sulfuric acid and potassium dichromate, was washed and rinsed with distilled water, and was covered with a plastic plate during measurements.

\section{Experimental results}

Some examples of the change of oxygen concentration with reaction time are shown in Figs. 3 and $\mathbf{4}$. The oxygen concentration within the first minute of the reaction time is not shown, since in this period the auxiliary stirrer was used to agitate the solution and thus a stable diffusion current could not be obtained. In Fig. 3, the calculated variation of oxygen concentration, which will be described later, is also plotted in a dotted line. At a constant oxygen concentration, higher sulfite concentration caused a remarkable decrease in the oxygen concentration per unit time at approximately the same solution $\mathrm{pH}$, as shown in Fig. 3. When these data are compared with those for sodium sulfite oxidation, it is seen that the oxidation rate of ammonium sulfite is about one tenth that of sodium sulfite where the sulfite concentration is $10^{-2} \mathrm{M}$ and the oxygen concentration is $10^{-3} \mathrm{M}$ at $25^{\circ} \mathrm{C}$. Fig. 4 shows the influence of $\mathrm{pH}$ of the solution on the reaction rate. At a constant sulfite concentration, higher hydrogen ion concentration yielded fast oxygen consumption.

The two different methods of starting the run, i.e., adding the sulfite solution to the oxygen-saturated solution and stopping of bubbling oxygen into the sulfite solution, yielded no difference in the observed rate.

Reaction rates were determined from graphical differentiation of the oxygen concentration-time curve at various oxygen concentrations. The rates were corrected for desorption or absorption, since the change of oxygen concentration as described above was resulted

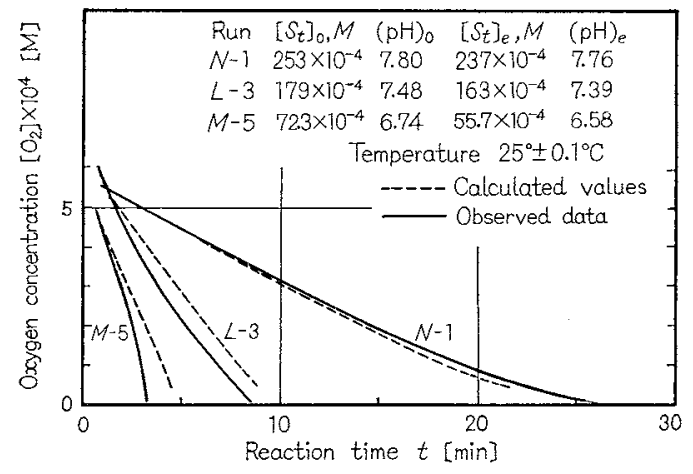

Fig. 4 Change of oxygen concentration with reaction time

both from consumption by the reaction and from desorption from or absorption into the solution.

Effect of the sulfite concentration on the rate At first, bisulfite, sulfite and total sulfite ions were taken into account as the reactant component which affected the rate, and the relations between the observed rates and the concentration of each of these three components were examined. The rates had no obvious correlation to the bisulfite concentration. The plot of the rate against the sulfite concentration resulted in the three-halves power relation at a constant $\mathrm{pH}$, as shown in Fig. 5. The total sulfite concentration showed almost the same correlation with the rate at a constant $\mathrm{pH}$ as did the sulfite concentration. This is reasonably explained from the ionization equilibrium between sulfite and total sulfite ions.

Effect of the oxygen concentration on the rate The relation of $r /\left[\mathrm{SO}_{3}{ }^{2-}\right]^{3 / 2}$ versus $\left[\mathrm{O}_{2}\right]$ is shown in Fig. 6. Over a wide range of oxygen concentration, the reaction rate was found to be independent of oxygen concentration. The reaction rate seemed to deviate from the zero-order relation in high and low oxygen concentration ranges, but in these ranges the data were not accurate enough to draw any conclusion.

Effect of $\mathbf{p H}$ on the rate The $\mathrm{pH}$ of the solution decreased as the reaction proceeded. The lower the initial $\mathrm{pH}$ of the solution, the more remarkable was the extent of this decrease. By using data from runs with solutions of various initial $\mathrm{pH}$, the reaction was found to be second order with respect to hydrogen ion concentration in the range of initial $\mathrm{pH}$ from 6.55 to 8.03 as shown in Fig. 7 .

From the experimental results described above, the rate equation for the ammonium sulfite oxidation was obtained as follows:

$$
r=k\left[\mathrm{SO}_{3}{ }^{2-}\right]^{3 / 2}\left[\mathrm{O}_{2}\right]^{0}\left[\mathrm{H}^{+}\right]^{2}
$$

Effect of temperature on the rate The plot of the reaction rate constant $k$ in Eq. (2) against the reciprocal of absolute temperature is shown in Fig. 8. The apparent activation energy is about $35 \mathrm{kcal} / \mathrm{mol}$ and the reaction rate constant can be expressed by the following equation.

$$
k=1.6 \times 10^{39} \exp \left(-35 \times 10^{3} / R T\right)
$$

Effect of the reactor size The results of runs using 


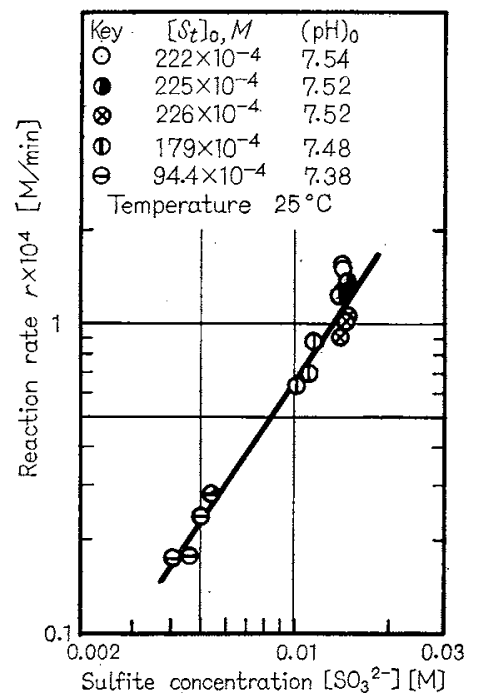

Fig. 5 Effect of sulfite concentration on reaction rate

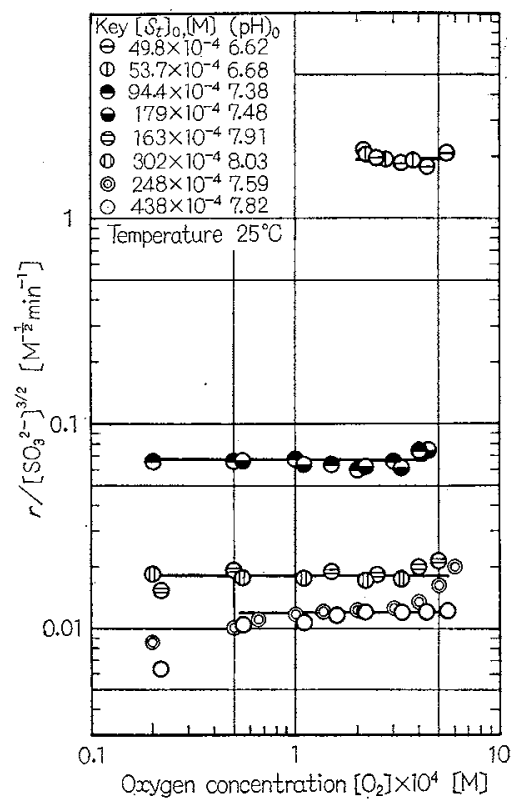

Fig. 6 Effect of oxygen concentration on reaction rate

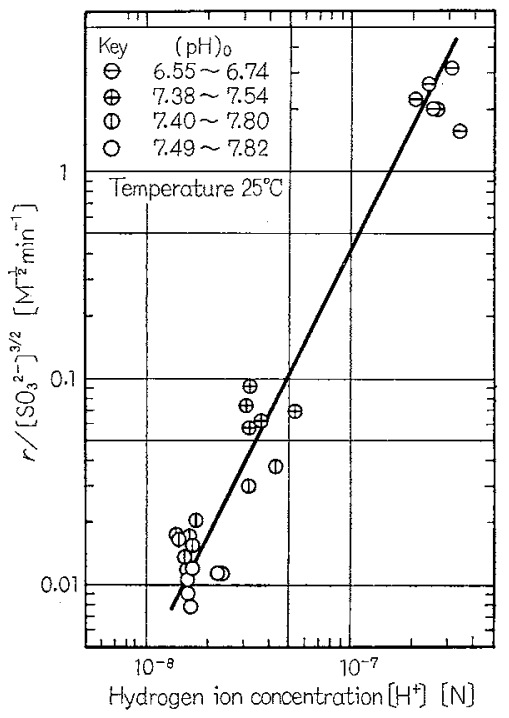

Fig. 7 Effect of hydrogen ion concentration on reaction rate the two different reactors showed no difference with respect to the reaction order. The reaction rate constant obtained in the small reactor, however, was about forty percent larger than that in the large one. This numerical difference may be owing to the presence of minute impurities in the solution, since the reaction is very sensitive to impurities as will be discussed later. When many instruments such as stirrer, bubbler, and the pH meter probe were placed in the reactor, there would be inevitably a possibility of impurities entering into the solution and it is probable that the concentration of impurities in the small reactor would be higher than that in the large reactor.

\section{Discussion}

Employment of the platinum electrodes In this study the polarographic method was employed to determine the oxidation rate of ammonium sulfite in aqueous solutions. The dissolved oxygen concentration during the reaction could be followed satisfactorily with good reproducibility when before each run the electrodes were immersed in $5 \mathrm{~N}-\mathrm{HNO}_{3}$ and $2.7 \mathrm{~V}$ of potential was applied to the electrodes, with the microelectrode being anode, to clean and condition the electrode surface. As it is known that platinum has catalytic effects for some reactions, the following test runs were carried out to determine if the sulfite oxidation was catalysed by platinum. The surface area of the anode plate was varied by coating with paraffin wax and reaction runs were carried out. No difference was found in the observed rate.

Effect of catalyst The significant feature of sodium sulfite oxidation is its marked sensitivity to catalysts such as heavy metal ions and organic compounds ${ }^{3,10,163}$. In fact, the ammonium sulfite oxidation proceeded

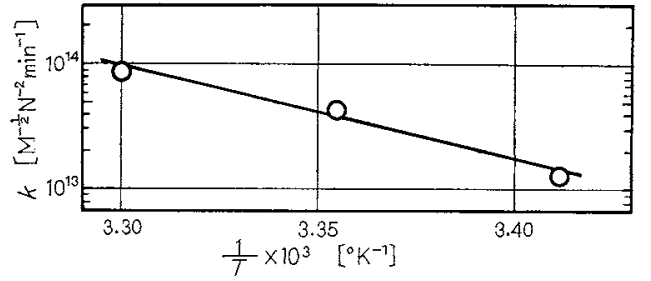

Fig. 8 Effect of temperature on reaction rate

remarkably fast when the ammonium sulfite solution contacted brass for only several tens of seconds, and the reaction was inhibited by adding about $1 \%$ of isopropylalcohol to a reacting solution. The existence of inhibitors suggests that the reaction may be a radical one ${ }^{133}$.

Comparison with the previous kinetics of sodium sulfite oxidation Barron and O'Hern ${ }^{3}$ investigated the homogeneous reaction of dissolved oxygen and sodium sulfite by using the rapid-mixing flow method of Hartridge and Roughton ${ }^{6)}$. Barron and O'Hern obtained a rate equation of three-halves order with respect to sulfite and zero order to oxygen. Their result is consistent with that of the present work for the reaction order with respect to sulfite and oxygen. It is known that many liquid-phase oxidations of organic compounds proceed by radical steps and that the reactions are zero order with respect to oxygen ${ }^{13}$. In this sense the mechanism of ammonium sulfite oxidation in aqueous solutions may be analogous to that of organic compounds.

To explain the kinetics of sulfite oxidation in aqueous solutions, many reaction mechanisms have been proposed and chain mechanisms have received a wide acceptance $^{2)}$. Free-radical chain mechanisms were proposed by $\mathrm{Abel}^{1)}$ and Bäckström ${ }^{2)}$. According to the 
theories, $\mathrm{SO}_{3}{ }^{2-}$ radical ${ }^{2)}$ and $\mathrm{HSO}_{3}{ }^{-}$radical ${ }^{1 \text {, }}$, respectively, function as the active centers of chains.

Using the elementary reaction scheme of Bäckström together with a few following assumptions, it is possible to derive a rate expression. The assumptions are: (i) the initiation of a chain occurs by a reaction of sulfite and hydrogen ions giving $\mathrm{SO}_{3}{ }^{\rightarrow}$ radical. (ii) the oxygen addition step

$$
\mathrm{O}_{2}+\mathrm{SO}_{3}^{-} \longrightarrow \mathrm{SO}_{5}^{-}
$$

is rapid and does not limit the over-all rate, and (iii) the termination occurs primarily by the combination of two ${ }^{~} \mathrm{SO}_{5}{ }^{-}$radical ions to form inert products. An application of the steady-state assumption to radicalion concentrations then leads to the following rate expression :

$$
r=k^{\prime}\left[\mathrm{H}^{+}\right]^{1 / 2}\left[\mathrm{SO}_{3}{ }^{2-}\right]^{3 / 2}\left[\mathrm{O}_{2}\right]^{0}
$$

The reaction order of this equation is consistent with the order in the empirical equation, Eq. (2), with respect to both oxygen and sulfite, but not to hydrogen ion.

Fuller and Crist ${ }^{4}$ studied the reaction in a closed reactor with adequate stirring of a solution in contact with oxygen. The result of Fuller and Crist, whose measurements were carried out within a short run time and will need a careful examination of the data, showed that the reaction rate was approximated to be proportional to the square root of the hydrogen ion concentration in the $\mathrm{pH}$ range of 3.2 to 5.9 , and independent of the hydrogen ion concentration in the $\mathrm{pH}$ range of 8.2 to 8.8 . Yagi and Inoue ${ }^{16)}$ made experiment by the polarographic method using the dropping mercury electrode in the $\mathrm{pH}$ range of 8.0 to 9.2 , and reported that the reaction was independent of the hydrogen ion concentration. However, the present work revealed that the reaction was remarkably influenced by hydrogen ion in the low $\mathrm{pH}$ range.

Fuller and Crist ${ }^{4}$ and Schroeter ${ }^{11}$ represented the reaction as first order in sulfite and bisulfite, respectively, at a constant oxygen concentration. Yagi and Inoue ${ }^{16)}$ reported that the reaction was first order with respect to both oxygen and sulfite. It is not clear why such various conclusions were drawn. Further study, especially of the reaction mechanism, will be necessary.

Comparison with the calculated variation of oxygen concentration The oxygen concentration as a function of time is obtained by the integration of Eq. (2) with Eq. (3) for $k$.

Some of the calculated variations of the oxygen concentration are plotted in dotted lines in Figs. 3 and 4. The calculated oxygen concentration is in fairly good agreement with the observed value. aqueous solutions was studied by batchwise experiment. The change of oxygen concentration was followed satisfactorily in good reproducibility by the polarographic method using the platinum microelectrode. The oxidation of ammonium sulfite was found to be much slower than that of sodium sulfite. The reaction was three-halves order with respect to sulfite, zero order to oxygen and second order to hydrogen ion in the concentration range of this work. The free radical chain mechanism of Bäckström could explain the dependencies on the sulfite and oxygen concentrations. The apparent activation energy of the reaction was found to be about $35 \mathrm{kcal} / \mathrm{mol}$.

\section{Nomenclature}

$k=$ reaction rate constant

$k^{\prime} \quad=$ reaction rate constant in $\mathrm{Eq}$. (4)

$K_{2}=$ apparent second ionization constant of sulfurous acid

$r \quad=$ reaction rate, $-\mathrm{d}\left[\mathrm{O}_{2}\right] / \mathrm{dt}$

$t=$ time

$T \quad=$ absolute temperature

$V_{\mathrm{SCE}}=$ potential to the saturated calomel electrode

$\left[\mathrm{M} \cdot \min ^{-1}\right]$

$[\min ]$

$\left[{ }^{\circ} \mathrm{K}\right]$

[volt]

Subscript

$\mathrm{o} \quad=$ refers to initial condition

e $\quad=$ refers to final condition

\section{Literature cited}

1) Abel, E.: Monatch. Chem., 82, 815 (1951)

2) Bäckström, H. I. J.: Z. physik. Chem. B 25, 122 (1934)

3) Barron, C. H. and H. A. O'Hern: Chem. Eng. Sci., 21, 397 (1966)

4) Fuller, E. C. and R. H. Crist: J. Am. Chem. Soc., 63, 1644 (1941)

5) "Gmelins Handbuch der anorganischen Chemie", System 9, Teil B, p. 467, Verlag Chemie G.m. b. H., Veinheim, 1960

6) Hartridge, H. and F. J. W. Roughton: Proc. Roy. Soc. London, A 104, 376 (1923)

7) Hori, S.: Nippon Gakujutsu-Kyokai Hokoku, 13, 570 (1937)

8) "Kagaku Benran (Handbook of Chemistry)", p. 868, Nippon Kagaku-kai, Maruzen Co., Tokyo, 1958

9) "Shin Bunseki-kagaku Koza", No. 10, p. 38, Kyoritsu Shuppan Co., Tokyo, 1960

10) Schroeter, L. C.: J. Pharm. Sci., 52, 559 (1963)

11) Schroeter, L. C. : ibid, 52, 564 (1963)

12) Sherwood, T. K. and R. L. Pigford: "Absorption and Extraction", 2nd ed., pp. 383-6, McGraw-Hill Book Company, Inc., New York, 1952

13) Tanaka, T.: "Yuriki-no-kagaku (Chemistry of Free Radical)", Tokyo Kagaku Dojin, Tokyo, 1965

14) Terres, E. and A. Heinsen: Gas-Wasserfach, 72, 994 (1929)

15) Vorländer, D. and A. Lainau: J.pr. Chem. 123, 351 (1929)

16) Yagi, S. and H. Inoue: Chem. Eng. Sci., 17, 411 (1962)

17) Young, S. L.: I. Am. Chem. Soc., 24, 297 (1902)

\section{Conclusion}

The homogeneous oxidation of ammonium sulfite in 